\title{
COLUSÃO NOS NEGÓCIOS JURÍDICOS PROCESSUAIS E A APLICAÇÃO DE UMA NOVA TEORIA DAS INVALIDADES PROCESSUAIS
}

\author{
SHAM IN PROCEDURAL AGREEMENTS AND THE APPLICABILITY OF A NEW PROCEDURAL \\ VOIDNESS DOCTRINE
}

Natasha Reis de Carvalho Cardoso*

\begin{abstract}
Resumo:
$\mathrm{O}$ artigo visa analisar a colusão entre as partes nas convenções processuais e identificar as suas consequências sob a ótica de uma nova teoria das invalidades processuais, ou seja, como uma exemplificação de sua execução casuística. A cláusula geral de negociação processual prevista no art. 190 CPC, máxima configuração da autonomia privada da vontade, consagrou a possibilidade de haver a atipicidade neste instituto. Desta forma, seria possível que determinadas disposições não previstas em lei pudessem ser objeto de convenção. No entanto, esta autonomia, se levada ao extremo e sem certos limites, pode facilitar a configuração de atos ilícitos pelos sujeitos processuais como vícios de consentimento (coação, lesão) ou vícios sociais (simulação, fraude contra credores). Por isso, para evitar que tais atos deturpem o instituto, faz mister analisar as suas consequências no plano processual. Por este motivo, impor-se-á um estudo da invalidade do ato jurídico a depender do caso concreto, utilizando-o também como exemplo de aplicação.
\end{abstract}

Palavras-chave: Direito Processual Civil. Convenções Processuais. Simulação. Colusão. Invalidade Processual.

\begin{abstract}
:
This paper aims to analyze the sham in the Procedural Agreements between the parties. In the Brazil's Civil Procedural Law there is a general clause about Procedural Agreements (article 190), which entails the possibility of atypical contents under this doctrine. Therefore, it would be possible that some rights or obligations, which are not established in accordance with the Law, could be a content of Procedural Agreements. However, this autonomy, if limitless applied, could entails illegal acts by any of the parties, for instance, "agreement's defects (duress, fraud, mental reservation) or 'social defects' (sham transaction or fraud against the creditors). Because of this fact, the present paper aims to study how to deal with sham in procedures, through the study of a new procedural voidness doctrine, which pursues the appliance of the nullity, depending on the case and seeking for a correction in the defects. Furthermore, it will be studied this doctrine through the legal transaction doctrine.
\end{abstract}

Keywords: Civil Procedure Law. Sham transactions. Procedural Agreements. Procedural Voidness.

Bacharela em Direito pela Faculdade de Direito da Universidade de São Paulo. 
Introdução

O presente artigo possui dois pontos centrais: os negócios jurídicos processuais, com a possível colusão das partes neste instituto e a aplicação da teoria das invalidades processuais, através de uma nova proposta de sistematização. A interrelação entre estas esferas se deu com o uso da colusão nos negócios jurídicos como uma exemplificação da aplicação ao caso concreto da teoria das invalidades.

As convenções processuais, inicialmente restritas à esfera da tipicidade estrita da lei, sob as modalidades clássicas da eleição de foro, suspensão convencional do processo e distribuição convencional do ônus da prova, por exemplo, passam a ter diversas outras possibilidades com o reconhecimento da atipicidade no instituto. Essa admissão fez jus às crescentes complexidades nas relações jurídicas processuais e econômicas, principalmente ao visar maior flexibilidade procedimental, consonante às necessidades dos litigantes.

Por isso, é de se reconhecer que as convenções processuais possuem inúmeras vantagens, tanto para as partes, quanto para a sociedade, ao se trazer maior eficiência processual, celeridade processual (quando se assume determinado compromisso ao longo do procedimento, por exemplo), ao mesmo tempo que se traz maior previsibilidade e segurança jurídica; além da redução dos custos de transação, sejam eles psicológicos ou financeiros.

\section{Relevância do tema}

Apesar das inúmeras vantagens que as convenções processuais trazem para a sociedade como um todo e de seu futuro promissor no meio processual, seu estudo ainda padece de lacunas. São questões como, qual seria a delimitação clara do objeto possível das convenções processuais; quais seriam os parâmetros e critérios que deveriam ser observados pelo juiz ao avaliar a validade das convenções (CABRAL, 2016, p. 168); se haveria a possibilidade de se observar tal matéria no direito penal, ${ }^{1}$ ou no direito empresarial; ${ }^{2}$ quais seriam os limites da negociação (NOGUEIRA, 2018, p. 183); se estariam sujeitos a termo ou condição, ${ }^{3}$ ou se seria passível de existirem no processo de

1 Já existem atualmente algumas possibilidades de convenção na esfera penal, apesar de ser uma área precipuamente pública, como a aplicação participativa e negociada da pena, a colaboração premiada, transação penal, suspensão condicional do processo, composição civil dos danos (art. $3^{\circ}$, I e $4^{\circ}, \S^{4^{\circ}}$ da Lei n. 12.850/2012).

2 A doutrina brasileira do processo civil ainda não examinou o Instituto das convenções processuais à luz da dogmática dos contratos empresariais, que seria bem diferente dos contratos convencionais e que por isso mereceria maior atenção (ARAGÃO; DIDIER JR; LIPIANI, 2018, p. 170).

3 Pedro Henrique Nogueira (2018, p. 210) em sua Tese de Doutorado a respeito do tema afirmou que tal 
execução. ${ }^{4}$ Outras questões ainda mais técnicas se impõem à matéria, como por exemplo, a viabilidade da parte que sofreu uma quebra contratual nos negócios jurídicos processuais acordados de verem compensados seus direitos por reparação de danos ou então de verem decisões invalidadas por conta do comportamento contrário ao estipulado em convenção de uma das partes. ${ }^{5}$

Assim, o art. 190 do CPC, apesar de trazer à baila as convenções processuais, encerra um regramento que não disciplina nem mesmo em termos genéricos inúmeros aspectos fundamentais dessa matéria. Por isso, há uma patente necessidade de se fornecer minimamente respostas sobre as esferas jurídicas que circundam o tema dos negócios jurídicos processuais.

Uma das matérias que padece de estudo também nesta esfera é o referente aos vícios sociais. Apesar do reconhecimento doutrinário, conforme pressupõe o Enunciado n. 132 FPPC, ${ }^{6}$ suas nuances e principalmente consequências ainda são pouco estudadas.

Por isso, o intuito do presente trabalho é trazer algumas reflexões sobre a matéria, através da análise de uma possível colusão nas convenções processuais e como seriam as suas consequências no plano da teoria das invalidades processuais, já se utilizando de uma moderna premissa de aplicação dela ao caso concreto.

Estrutura do artigo

Para tanto, optou-se por dividir o artigo em três partes essenciais. A primeira trouxe alguns pressupostos essenciais para se compreender as convenções processuais. A segunda parte pretendeu trazer definições e aplicações da simulação tanto na seara civil quanto na processual. Por fim, como uma inter-relação entre a primeira e segunda parte, intentou-se na terceira trazer um panorama geral da teoria das invalidades, com uma nova proposta de sistematização e aplicação conforme o caso concreto.

assunto seria uma dúvida e um dos grandes problemas ligado ao estudo desta matéria, a respeito do qual, no Brasil, pouco se elaborou.

4 Fredie Didier Jr. (2018a, p. 64) afirmou que já foi notado na doutrina que o interesse acadêmico e prático pelos negócios jurídicos processuais executivos não era tão comum quanto em relação aos negócios das partes em outros tipos de processo. Por isso, teria uma grande lacuna em torno do tema.

5 Na Alemanha, por exemplo, já se discutiu sobre essa questão, e uma corrente minoritária da doutrina acredita que as únicas sanções cabíveis para o não cumprimento do prometido na convenção processual seriam perdas e danos. Outra corrente de autores afirma que se a parte não realiza com o prometido e faz algo contrário do que estipulou em convenção, a declaração é inválida, invocando ainda que o oponente agiu de má-fé (exceptio dolis processualis) (KERN, 2015, p. 220).

6 Enunciado n. 132 FPPC: "Além dos defeitos processuais, os vícios da vontade e os vícios sociais podem dar ensejo à invalidação dos negócios jurídicos atípicos do art. 190”. 
1. Pressupostos das convenções processuais

Os negócios jurídicos se inserem dentro das categorias determinadas dos fatos jurídicos (lato sensu). Estes fatos jurídicos são classificados de forma didática e simplificada da seguinte maneira: ${ }^{7}$ i) fatos jurídicos em sentido estrito, que são aqueles determinados pela natureza e não praticados pelo homem; ii) atos jurídicos em sentido amplo, os quais são aqueles atos humanos voluntários. Dentro desta categoria são subdivididos em: ii.1) atos jurídicos em sentido estrito: são aqueles em que os efeitos decorrentes do ato já estão previstos em lei; ii.2) negócios jurídicos: são aqueles atos em que o sistema jurídico confere a possibilidade dos agentes decidirem qual será o conteúdo de eficácia de seus acordos, ou seja, quais serão os efeitos decorrentes do ato. Por isso, conferem um amplo grau de liberdade aos agentes.

Apesar desse breve panorama em relação a classificação dos fatos jurídicos, o que interessa na presente obra é a teoria dos negócios jurídicos (JUNQUEIRA DE AZEVEDO, 1986, p. 4-10), os quais reconhecidos desde a pré-história só vieram para a esfera processual depois de muita restrição e controvérsia. Essas limitações e polêmicas quanto à possibilidade de se dar tamanha autonomia às partes para modificar procedimentos se deveram basicamente pelo discurso da suposta intransponibilidade do direito público e privado: sobre o processo, caberia apenas ao Estado regular.

Esse discurso deu ensejo ao embate doutrinário a respeito do tema, mas, por fim, ele foi aceito de forma expressa no ordenamento jurídico brasileiro. ${ }^{8}$ Barbosa Moreira (2007, p. 87-102), por exemplo, foi um dos defensores da adoção deste sistema. $\mathrm{O}$ autor advogava pelo reconhecimento aos indivíduos de suas capacidades e liberdades de negociação, de criação (possibilidade de criar modelos negociais atípicos que melhor sirvam aos interesses dos indivíduos), estipulação (faculdade de estabelecer o conteúdo do negócio) e de vinculação (faculdade de celebrar ou não o negócio) do que haviam acordado para poderem produzirem suas próprias normas jurídicas individuais. ${ }^{9}$ São estas quatro zonas de liberdade que preponderaria na feitura dos negócios jurídicos (NOGUEIRA, 2018, p. 156-157), tanto daqueles do direito civil, quanto dos processuais. ${ }^{10}$

Pontes de Miranda realizou o estudo dessa classificação nas seguintes obras: Miranda (2012, v. 2) e Miranda (2012, v. 3).

8 Este reconhecimento teve como base o próprio regramento de negócios jurídicos do direito civil, em que diversas cautelas foram feitas ao se transportar conceitos preponderantemente da esfera cível para a processual. Uma das grandes protagonistas nesta reflexão foi Paula Sarno Braga (2010, p. 445-474).

9 Hans Kelsen (1999, p. 103-104) já afirmava que a capacidade negocial seria o poder jurídico conferido pela ordem jurídica aos indivíduos, para em conformidade com as normas jurídicas gerais, criarem também direitos e deveres, isso também através dos negócios jurídicos.

10 Nesse sentido, as convenções processuais seriam consideradas como mais um instrumento de emancipação civilizatória, ao se permitir o que chamou de self-governance processual (DAVIS; HERSHKOFF, 2015, p. 165-166). Desse poder de governança, advém o princípio do in dubio pro libertate, ou seja, uma 
Reconhecido o negócio jurídico à relação processual, restou indagar sobre a sua terminologia. Foram diversos os conceitos até então utilizados, como "acordos", "contratos", "cláusulas" ou "convenções", e muitas vezes, conhecidas por "pacto" ou "protocolo". Sem excluir as mais diversas conceituações, o presente artigo preferiu adotar a tratativa "convenção", ${ }^{11}$ com a definição já consagrada e estudada por Antônio do Passo Cabral (2016, p. 73): “é o negócio jurídico plurilateral pelo qual as partes, antes ou durante o processo e sem necessidade da intermediação de nenhum outro sujeito, determinam a criação, modificação e extinção de situações jurídicas processuais, ou alteram o procedimento".

\subsection{Limites à autonomia privada}

Apesar da admissão da autonomia privada na esfera processual, é errado pensar que a negociação seria um domínio exclusivo de interesses privados (CABRAL, 2016, p. 364). Nem mesmo no direito civil esta concepção se sustenta. A negociação possui consequências e efeitos muito além daqueles restritos às partes, refletindo na sociedade como um todo. Por esse motivo, é imprescindível conformar os interesses particulares com o interesse público, limitando-se a livre disposição (CABRAL, 2016, p. 170).

Essa limitação é regrada pelo ordenamento, que trouxe restrições tanto formais, quanto materiais. Limites estes que serviriam também como um mecanismo paliativo a se afastar as críticas decorrentes de uma eventual "mercantilização do processo" ou redução do poder Estatal (CABRAL, 2016, p. 212).

Por isso, para serem válidas as convenções, seria imprescindível que: i) houvesse o respeito ao princípio de determinação, ou seja, que a convenção fizesse referência a uma relação jurídica ou conflito específicos; ii) se possível, incluísse um limite temporal (duração do acordo); iii) Se observasse os requisitos de validade dos negócios jurídicos que lei material traz, definidos no direito civil: agente capaz, objeto lícito e forma prescrita ou não defesa em lei (arts. 104 a 166 do CC); iv) As partes deliberassem

pressuposição às partes do litígio em favor da liberdade de conformação do procedimento pela vontade delas.

11 A controvérsia jurídica a respeito da terminologia correta para se referir aos negócios jurídicos processuais possui fundamental importância, já que através dela se permite averiguar sua natureza jurídica e assim observar a sua funcionalidade. Nesse sentido, como o propósito no trabalho é problematizar a simulação dos negócios jurídicos processuais, a qual depende primordialmente da vontade de ambas as partes e de seus interesses convergentes, utiliza-se o termo "convenções", já que melhor expressão que condiz com a vontade de ambas as partes em realizar o negócio. Desde logo utilizou tal terminologia para se referir aos negócios jurídicos processuais, já que afirmava ser a expressão de cunho mais técnico e aderente à linguagem do código que usa "Convenção" nos arts. 111, 181, 265, II, 333, parágrafo único e 453, I, bem como palavras cognatas em outros dispositivos (arts. 454, $\S 1^{\circ}, 606, \mathrm{I}, 656,792,1.028,1.031, \mathrm{I}, 1.113, \S 3^{\circ}$ CPC). 
apenas sobre situações jurídicas que estivessem em sua esfera de autonomia. (CABRAL, 2016, p. 87). Ou seja, não estariam autorizadas a dispor sobre segredo de justiça (DIDIER JÚNIOR, 2018b, p. 39), ${ }^{12}$ nem mesmo sobre o afastamento do MP do processo.

Em dissonância com estes limites surgem os eventuais vícios, e mais especificamente os atos simulados, que serão analisados nos próximos tópicos.

\section{A simulação}

\subsection{Simulação no direito civil}

O negócio jurídico simulado é conceituado no direito civil como aquele que tem uma aparência contrária à realidade, seja porque não existe em absoluto ou porque é diferente em sua aparência (FERRARA, 1939, p. 51). Nesse sentido, o vício ocorre quando dois contratantes, para seus fins particulares, ${ }^{13}$ propõem-se a enganar sujeitos externos ao negócio, para fazer-lhes acreditar que realizam um ato que realmente não queriam efetuar, apenas ansiando engendrar nos outros uma falsa representação de suas vontades (FERRARA, 1939, p. 51).

No CC/1916 se fazia uma certa diferenciação de dois tipos de simulação. Eram divididos, portanto, em duas espécies: aquelas que havia intenção de enganar alguém e de prejudicar terceiros (nocente - art. 102 do CC/1916) e aquela que não havia esta intenção (inocente - art. 103 e 104 do CC/1916). ${ }^{14}$ A primeira delas, sendo aparentemente mais grave, seria causa de nulidade; enquanto a segunda, menos prejudicial, seria motivo de anulabilidade. ${ }^{15}$ No entanto, essa divisão não teve mais respaldo legal no CC/2002, o qual consagrou qualquer tipo de simulação passível de nulidade.

A doutrina, portanto, por meio de uma interpretação literal da legislação do $\mathrm{CC} / 2002$, com base no dispositivo da simulação apontou que não haveria nenhuma

12 Não se admite acordo de segredo de justiça no Brasil até por imperativo constitucional (art. 5, LX; art. 93, IX, $\mathrm{X}$ da CF). Caso as partes desejem um processo sigiloso, deverão optar pela arbitragem. No entanto, na França, até pela falta de disposição constitucional, este tipo de acordo é permitido (art. 435, CPC francês).

13 A finalidade da simulação, ou seja, o que leva as partes à prática de tal ato e assim criação de um negócio aparente e não do que realmente intentam é que se denomina causa simulandi e que não se confunde com a causa do contrato (Cf. GAINO, 2007, p. 56-57).

14 Art. 103: "A simulação não se considerará defeito em qualquer dos casos do artigo antecedente, quando não houver intenção de prejudicar a terceiros, ou de violar disposição de lei”.

Art. 104: "Tendo havido intuito de prejudicar a terceiros, ou infringir preceito de lei, nada poderão alegar, ou requerer os contraentes em juízo quanto à simulação do ato, em litígio de um contra o outro, ou contra terceiros".

15 No CC de 1916 (arts. 102 a 105) a simulação podia ser também causa de anulação do negócio jurídico, isso porque se diferenciava entre a simulação nocente ou inocente. Apenas a nocente seria causa de nulidade, pois mais grave. No entanto, com o CC atual, retirou-se essa diferenciação e passou a ser causa de nulidade em qualquer hipótese, seguindo-se o modelo de outras legislações estrangeiras, como o BGB (§ 117) e a italiana (art. 1.414), em que considera a simulação causa de nulidade. 
distinção nessas duas classificações, e por isso não teria importância distinguir a simulação absoluta da relativa, bem como se prejudica alguém ou não. No entanto, não é a posição adotada no presente artigo, pois acredita-se que a inocência ou não do ato simulado não pode ser desconsiderada, ${ }^{16}$ já que possuem consequências diversas no plano processual.

Nesse sentido, se há ato simulado inocente, é possível considerar-se válido o ato dissimulado que estiver encoberto, desde que contenha os pressupostos adequados de validade, que dispõe o art. 167, caput, CC. Por meio deste procedimento, denominado "extraversão", faz surgir o ato autêntico, apesar de oculto, em prejuízo do simulador. Esta consequência decorre do próprio princípio da conversão dos negócios jurídicos, o qual determina a desnecessidade de se anular o negócio jurídico, caso haja possibilidade de aproveitá-lo.

No entanto, em sentido contrário teria a consequência de um ato simulado nocente. Já que este, em essência, é um ato ilícito. Portanto, a sua invalidade e consequente ineficácia alcançaria tanto o ato simulado quanto o dissimulado, não sendo possível se falar em conversibilidade, com ressalvas aos direitos dos terceiros de boa-fé. Estes seriam as consequências decorrentes do CC/2016, mas que no plano processual trariam outros efeitos (MELLO, 2008, p. 130-132).

Essa premissa tem grande relevância quando se for discutir a questão da teoria das invalidades nos atos jurídicos simulados na terceira parte do artigo, já que a delimitação das consequências e dos efeitos da colusão nas convenções processuais dependerão primordialmente de se considerar a diferenciação entre simulação nocente e inocente, ${ }^{17}$ em consonância com a defesa de uma leitura casuística da teoria das invalidades.

Nesse sentido e já adiantando futuros entendimentos na teoria das invalidades a ser apresentada, a questão de a simulação ser absoluta ou relativa possui grande influência ao se considerar a existência ou inexistência do negócio jurídico. ${ }^{18}$

\subsection{Simulação no processo civil: colusão}

No processo civil, a simulação é reconhecida como "colusão", assim conceituada como aquela "empregada para designar a combinação, a conivência, o conluio ou o pacto entre as partes que litigam simuladamente ou não, com o intuito de

16 Posicionamento de Marcos Bernardes de Mello (2008, p. 130) que é a adotada no presente artigo.

17 Luiz Carlos de Andrade Júnior (2016, p. 108-109) põe em relevo o fato de que o juízo sobre a nocência da simulação continua sendo relevante para algumas finalidades, e cita alguns exemplos, como: "para a aferição do interesse na declaração de nulidade do negócio simulado e para a definição de ulteriores desdobramentos desta, tais como a possibilidade de um dos simuladores obter a reparação por danos sofridos em virtude da simulação aos quais corresponda injustificado enriquecimento da contraparte.

18 Em sentido contrário Bevilaqua (1927, p. 345), em que condenava a simulação em todos os casos, seja ela "inocente" ou nocente. 
enganar o juiz, com prejuízo de terceiro" (ENCICLOPÉDIA SARAIVA DO DIREITO, 1977, p. 150-151).

Apesar do conceito já estar consolidado na doutrina processual, nem sempre foi assim. Havia discussão a respeito da possibilidade ou não de haver simulação no processo civil. A tendência era de se acreditar que o acordo simulatório seria inviável por faltar a concórdia de todos os participantes da relação processual, ou seja, por faltar a participação do magistrado, que exerceria a autoridade pública e por isso seria estranho à intenção real dos litigantes. ${ }^{19}$ Outros, justificavam a impossibilidade por meio do argumento de que o processo seria uma relação de direito público e não privado, e que, consequentemente a figura do juiz seria externa ao objeto simulatório. ${ }^{20}$

No entanto, reconhecida a existência, ela passou a ser delimitada como aquela em que as partes intentam conseguir um resultado diverso do pedido em inicial, e que coincidirá com as consequências processuais. Assim, procuram obter com a sentença judicial que alguém seja obrigado a ceder um direito ou a assumir uma obrigação querida apenas na aparência (GAINO, 2007, p. 143-144).

\subsection{Colusão nas convenções processuais}

Importante ressaltar que a simulação processual não ocorre apenas com a propositura de um certo processo simulado, havendo este quadro também quando se celebra uma convenção processual, em que as partes dispõem sobre alguma alteração procedimental na lide $^{21}$ querida apenas fictamente. Nesse caso, aplicar-se-ia o art. 142 do CPC, o qual impõe ao juiz o dever de proferir decisão que coíba a intenção fraudatória das partes. Por isso, pode-se afirmar que a simulação processual constitui, assim como a fraude à lei, modalidade de abuso do processo. Está revestida de todos os elementos caracterizadores do abuso e ainda contido numa aparência de legalidade (ABDO, 2007, p. 153). Por isso, parte da doutrina o caracteriza como forma de abuso macroscópico, que ocorre quando um sujeito processual faz mau uso do processo como um todo (ABDO, 2007, p. 189).

Assim, a repressão deste ato por parte do juiz ou do terceiro prejudicado é imprescindível e encontra duplo motivo para sua observância (STROPA GARCIA, 1993,

19 Essa concepção era a predominante e vanguardeada por Héctor Cámara (1944, p. 129-130) e Francisco Ferrara (1939, p. 143) que sustentava fortemente a impossibilidade de haver simulação no processo.

20 Francisco Ferrara (1939, p. 132-134) era favorável a essa posição, apesar de admitir as mesmas influências subjetivas e objetivas do direito material ao processo.

21 Cf. Didier Jr. (2018b, p. 38): "As convenções processuais remetem a temas muito técnicos, o que ressalta o perigo de que a disposição sobre garantias processuais inviabilize ou torne muito oneroso o exercício dos direitos materiais, podendo também camuflar situações de ilicitude, ou então de renúncia a direitos fundamentais sobre pelas convenções". 
p. 255-256): primeiro por conta do uso do processo fora de suas finalidades; segundo por conta da fraude às normas de direito substancial. Nesse sentido, é essencial a discussão da simulação nas convenções processuais, porque além de atuar de forma abusiva à demanda microscópica, ainda deturpa as finalidades específicas das convenções processuais. ${ }^{22}$

\subsection{Projeções e manifestações no processo}

Como manifestação prática do instituto da colusão, pode-se citar alguns exemplos, que também podem ser expandidos às convenções. Uma delas é a declaração de débito sob forma de confissão judicial apenas para constituir um título executivo judicial, sem verdade absoluta no que se afirmava. Já o negócio simulado seria o emprego do juízo com o objetivo de angariar um negócio que não se poderia validamente constituir ou de fazer crer existir um estado jurídico ou uma relação de crédito e débito que as partes considerariam entre elas inexistente.

Outro exemplo é quando o devedor simula com pessoa de sua confiança, acionando-o fictamente em juízo por um crédito fictício também, a fim de realizar um acordo simulatório. O objetivo seria a obtenção de uma sentença condenatória que constituiria título executivo e serviria para ingresso em concurso de credores ou para penhora. Com isso, constituiria uma preferência fictícia em relação ao credor também fictício em detrimento dos credores reais, para que estes ficassem sem garantia patrimonial para satisfação de seus créditos (GAINO, 2007, p. 140-141).

Além disso e no mesmo exemplo realizado, pode haver penhora do patrimônio disponível pelo credor fictício, havendo, no curso do processo, a remição dos bens pela esposa ou por parente do falso devedor. ${ }^{23}$ Assim, pode este credor fictício resgatar o bem apenas para que este fique livre de outras execuções. A remição ainda será feita mediante depósito de valor da arrematação ou adjudicação, o que, segundo os ditames de um acordo simulatório no início engendrado, será levantado pelo credor fictício e posteriormente entregue ao devedor fictício (GAINO, 2007, p. 71).

Outro exemplo é quando ocorrer durante o curso de um procedimento executório real. Ou seja, o devedor real realiza um contrato com simulação de data (expediente de antedatação) com outrem sobre um bem que já havia sido supostamente vendido a este. Assim, aparece no meio do processo de execução este terceiro que está

$22 \quad$ Helena Najjar Abdo (2007, p. 141) afirma que um dos principais critérios definidores do abuso do direito e também do abuso do processo é o desvio de finalidade na prática de determinado ato ou, mais precisamente, no exercício de uma situação jurídica processual.

23 Art. 674: Quem, não sendo parte no processo, sofrer constrição ou ameaça de constrição sobre bens que possua ou sobre os quais tenha direito incompatível com o ato constritivo, poderá requerer seu desfazimento ou sua inibição por meio de embargos de terceiro. 
em colusão com o devedor real afirmando ser dono ou possuidor do bem penhorado, interpondo embargos de terceiro (art. 674 do CPC). Este terceiro apresenta como prova de sua posse um contrato particular em que a data do bem alienado é anterior à data da execução, entretanto, é falsa. Assim, o devedor fictício se vê protegido de possível penhora de seu patrimônio ou bens através deste contrato aparente.

3. Consequências da colusão no negócio jurídico: a teoria das invalidades

3.1. Panorama da teoria das invalidades

Após breves exemplificações práticas e reconhecida a sua possibilidade nas convenções processuais, passa-se à discussão das consequências deste vício no instituto.

Tradicionalmente, grande parte das ideias da teoria das invalidades receberam as primeiras formações na doutrina civilista. Atualmente também já se reconhece que o plano da validade do negócio jurídico também pode ser inserido a outros ramos, como o direito processual civil, administrativo ou até penal. No entanto, o grande desafio que se impôs inicialmente foi como se transpor esses conceitos e ideias para as outras esferas do direito, como no processo (SICA, 2008, p. 184) e como conciliar ambos os instrumentos.

Ao responder a indagação, parece que o caso não é de preponderância ou subordinação de um a outro, mas sim de conexão e complementariedade. Isso porque já se tem a ideia de que as regras sobre as nulidades dos atos jurídicos em geral podem ser aplicadas no processo, se houver um certo cuidado em sua adaptação e em seu conceito, que atua de forma diversa no direito material e processual (CABRAL, 2010, p. 19).

Além disso, atualmente a questão sobre qual instrumento aplicar parece ter perdido o sentido. Primeiro porque o CPC/1973 e o atual possuem uma seção específica para tratar dos atos processuais e das nulidades, o que facilita muito a delimitação temática e a produção de seus efeitos. Segundo porque a doutrina e jurisprudência já estão mais passíveis a aceitar a aplicação analógica da disciplina das invalidades no direito privado, se houver compatibilidade com o direito processual civil (CABRAL, 2010, p. 19), se se atentar para as peculiaridades do ato jurídico processual, e se forem observadas as características próprias e peculiares de cada sistema (CABRAL, 2010, p. 20).

Nesse sentido, considerando que após a formação da relação jurídica processual o negócio jurídico vê seus efeitos serem processualizados, parece adequado que se aplique para o juízo de cognição o sistema de formas e invalidades processuais, e não apenas as regras de direito material (CABRAL, 2016, p. 289), assim como é possível cogitar da sujeição das convenções processuais a um duplo regime, principalmente na esfera das invalidades (NOGUEIRA, 2018, p. 196). 
Apesar da sujeição e complementariedade dos dois regimes, mister salientar a diferenciação de efeitos nos dois âmbitos do direito, já que eles não são os mesmos. Mesmo que tenham um tronco comum na teoria geral do direito, ${ }^{24}$ ambas as teorias são autônomas em seu regramento (SILVEIRA, 2005, p. 711). A grande questão, portanto, é discutir a respeito das situações que há nulidade ${ }^{25}$ ou anulabilidade, assim como as diferenciações que permeiam os dois ramos.

Uma diferenciação seria quanto ao próprio caráter dos atos jurídicos: os atos processuais se inserem numa cadeia de eventos, unidos por uma coesão indissociável entre si, e, consequentemente devem ser analisados em conjunto (CABRAL, 2010, p. 21); no direito material já se pode ter uma compreensão deles de forma muito mais estanque ou compartimentada. Outro exemplo diferenciador é a divisão primordial entre nulidade e anulabilidade na esfera civil, em que apenas no caso deste último seria possível convalidação do ato, já que o primeiro regularia interesse público, e o segundo, privado.

Já o sistema processual determinou duas principais classificações de nulidades que merecem destaque. A primeira, de enorme repercussão - porque prevalecente até hoje $\mathrm{e}^{26}$ - divide as invalidades em três grandes espécies: nulidades absolutas, nulidades relativas e anulabilidade. Esta teoria veio com Carnelutti (1936, p. 488-490), que classificando de maneira tricotômica a teoria das invalidades, teria adotado para tanto dois principais critérios: a) natureza da norma que estabelece a exigência da forma; b) interesse protegido pela norma.

${ }_{24}$ Roque Komatsu (1991, p. 25-26) menciona que na verdade, não há uma transposição de conceitos do direito civil para a seara processual, mas que há sim um "superconceito" ou "noção categorial" dos vários institutos jurídicos e que sendo comuns, devem ser colocados na teoria geral do direito e não do código civil.

25 Importante salientar que há alguns doutrinadores que sustentam ser o ato nulo juridicamente inexistente. Tal entendimento não é o adotado na presente tese, adotando o posicionamento de que o ato jurídico nulo é fato jurídico como qualquer outro só que de forma deficiente, e este defeito estaria no plano da invalidade e não no da inexistência. Além disso, a sustentação do ato nulo ser juridicamente inexistente já foi refutada por Marcos Bernardes de Mello (2008, p. 10-13), quando trouxe três dados no seu segundo volume que revelam claramente a opção dos sistemas jurídicos de refutar esta teoria: a) a eficácia do ato jurídico putativo; b) a possibilidade de conversibilidade do ato inválido, desde que atenda à vontade negocial dos figurantes do ato jurídico; c) necessidade de desconstituição do ato inválido e o fato do ato inexistente não precisar ser desconstituído judicialmente, já que nunca existiu.

26 Sistema de nulidades trazido por Galeno Lacerda (1953, p. 124-128), com base em Carnelutti (1936, p. 495-497). No entanto, mister salientar que tal teoria foi estruturada e desenvolvida em torno do Código de 1939 (por este motivo, não deveria ser aplicada fora desta legislação, mesmo com a grande similitude das leis de então para os textos legais atuais), a qual perdurou até os dias atuais sem alterações de relevo. Este ponto de grande relevância vem sendo criticado fortemente pela doutrina, já que o direito processual passou por diversas modificações, mas o sistema da teoria das invalidades continua petrificado Cf. Antônio do Passo Cabral (2010, p. 71-78). No entanto, mister salientar algumas mudanças positivas decorrentes do CPC na matéria, o qual consagrou o princípio do contraditório do juiz, em que este, antes de pronunciar as invalidades, deve dar vista às partes para se manifestarem; ou então o resgate da vontade na prática dos atos do processo ou a introdução do princípio da prevalência do exame de mérito. 
No primeiro critério poderia se diferenciar as nulidades das anulabilidades. Nesse sentido, as nulidades seriam estabelecidas por normas cogentes, imperativas, enquanto as anulabilidades seriam normatizadas por regras dispositivas. Quanto ao segundo critério se poderia diferenciar entre as nulidades absolutas e relativas. ${ }^{27}$ Seriam consideradas absolutas quando o interesse tutelado pela norma fosse público, ${ }^{28} \mathrm{e}$ consequentemente de vício insanável e, seriam relativas aquelas de interesse particular, podendo haver convalidação. ${ }^{29}$

\subsection{Proposta de nova sistematização e aplicação da teoria das invalidades}

Diversos autores, notando a insuficiência da teoria acima, trouxeram outras para solucionar as críticas que circundavam o assunto, como por exemplo Galeno Lacerda (1953, p. 72) com sua teoria dicotômica, ${ }^{30}$ ou Teresa Arruda Alvim Wambier (2004) se referindo às nulidades cominadas ou não cominadas, ou mais recentemente com a proposta de Heitor Sica (2019, p. 290-291), que priorizou quatro diferentes critérios para se atribuir a invalidade de um ato, defendendo que estes parâmetros não devem interagir de maneira estanque e linear, mas sim serem utilizados de forma simultânea de maneira que os raciocínios relacionados às quatro classificações sejam ad infinitum. ${ }^{31}$

Consoante a esta última solução, o presente artigo se filia à ideia de que a teoria das invalidades não deve ser aplicada exclusivamente pelo critério da natureza

27 Importante notar que Teresa Arruda Alvim Wambier (2004, p. 200-201) propõe uma divisão das nulidades diversa do binômio relativa-absoluta. A autora as divide em nulidade de fundo e nulidade de forma (ou de rito). As nulidades de fundo, seriam aquelas decorrentes dos vícios relacionadas às condições da ação, aos pressupostos processuais de existência e validade (pressupostos positivos), bem como todas as espécies de nulidades (pressupostos negativos). Já as nulidades de forma seriam aquelas que ocorrem quando a fórmula do ato não é seguida. Ou seja, quando a lei prevê um modo de se praticar o ato e este não é observado.

28 Outra crítica contundente apontada pela doutrina referente à teoria das invalidades processuais seria em relação a este critério do interesse tutelado, o qual traz uma progressiva gravidade das sanções de forma incorreta. Isto porque no processo não há interesse que atenda apenas a fins estatais e tampouco que interessem exclusivamente o interesse privado. Há a prevalência de ambos os interesses, principalmente após a publicização do direito processual. Em que aparentemente foi vencedora a concepção de que o processo não é coisa das partes. São múltiplos os interesses envolvidos em uma demanda judicial, ainda que seu objeto seja exclusivamente privado.

29 Humberto Theodoro Jr. (2016, p. 587-588) afirma que as nulidades absolutas ofenderiam regras referentes aos pressupostos processuais e condições da ação, e por isso não seriam passíveis de convalidação. No entanto, as nulidades relativas violariam faculdades processuais das partes, especialmente aos referentes ao devido processo legal e ampla defesa.

30 Para o autor a nulidade relativa seria decorrente de um vício sanável, por não se submeter ao interesse público, enquanto a segunda de um vício insanável, por ser condicionado a um interesse público.

31 Os critérios trazidos pelo autor foram: i) quanto ao sujeito que pode suscitar as invalidades, sendo classificadas entre cognoscíveis ex officio ou apenas provocação da parte; ii) quanto ao prazo de invocação, o qual podem ser divididas entre aquelas que não se sujeitam à preclusão e aquelas que não são sujeitas; iii) quanto à presunção do prejuízo ou não; iv) entre invalidades sanáveis e outras insanáveis (SICA, 2019, p. 291). 
do vício ou de sua gravidade, mas sim conforme os seus efeitos na relação processual. $\mathrm{Ou}$ seja, defende-se que a teoria das nulidades seja aplicada em dependência ao caso concreto, ${ }^{32}$ "dando-se maior elasticidade para apreciação da relevância da infração à forma no caso concreto, sem que se esteja preso a um rígido esquema legal ou doutrinário" (MITIDIERO, 2015, p. 126). Nesse sentido, analisa-se o vício do ato processual na perspectiva da obtenção da sua finalidade essencial e na ausência de prejuízo.

Por esse motivo, não se pode concordar que a categoria da teoria das nulidades processuais seja constante e invariável, como pregava Galeno Lacerda (1953, p. 70) até mesmo pelo próprio dinamismo da relação processual, a qual se constitui e se desfaz conforme o conjunto de condutas e a depender das peculiaridades do caso.

Com base nisto, defende-se que as consequências do negócio jurídico processual simulado se deem conforme o caso concreto, a depender do prejuízo ocasionado a terceiro e ao judiciário. É isto que se tem como reflexão no presente artigo.

\subsubsection{Exemplificação de aplicação ao caso concreto}

Não resta dúvida que o erro, dolo, coação e simulação são passíveis de justificar a nulidade do acordo processual. ${ }^{33}$ Nestes vícios, a convenção pode ser anulada porque o agente atua só aparentemente de maneira livre, sendo que na realidade sua declaração é viciada. ${ }^{34}$ Como uma reflexão a ser utilizada para posteriores estudos aprofundados sobre os vícios nos negócios jurídicos, é analisado brevemente como se aplicaria a teoria das invalidades na simulação. Para tanto, há algumas peculiaridades que merecem atenção e reflexão.

Uma delas é a que se encontra na possibilidade da colusão na convenção processual extrapolar a esfera microscópica e influenciar a sentença, tornando-se macroscópica, com a extensão do vício à demanda como um todo, o que possibilitaria também o ensejo da ação rescisória posterior, conforme art. 966, III CPC, ${ }^{35}$ observado

32 Tal concepção é defendida, dentre outros, por Antônio do Passo Cabral (2010, p. 88), e por José Roberto dos Santos Bedaque (2010, p. 445), o qual afirma: "Impossível construir a priori situações de atos processuais nulos. Qualquer conclusão a respeito somente será possível à luz do caso concreto, com a verificação da coincidência, ou não, entre o resultado alcançado com a prática do ato e o fim desejado pelo legislador".

33 Cf. Clóvis Bevilaqua (1927, p. 321), o erro seria uma falsa representação da realidade, uma percepção equivocada do acordo que faz com que a parte atribua ao próprio comportamento um significado diverso daquele que objetivamente tem. O CPC prevê o erro como um vício processual, já que também seria causa para ação rescisória (art. 966, VIII e $\S 1^{\circ}$ ). O dolo ocorre quando uma das partes induz a outra, através de um ardil, a formar uma falsa apreensão do acordo (ver alguma obra de civil, na parte de teoria geral do direito civil). A coação corresponderia à imposição de força física, pressionando a manifestação de vontade.

34 A manifestação da vontade, para integrar o suporte fático do ato jurídico há de ser autêntica, íntegra e rígida e o sistema jurídico brasileiro considera como defeito que afeta a perfeição dessa manifestação os vícios da vontade, que seria, um dos exemplos, no caso de simulação (MELLO, 2008, p. 38).

35 A sentença prolatada em processo simulado, fruto de simulação ou colusão entre as partes para fraudar 
o seu prazo de 2 anos. Apesar de se ter a discussão do vício permanecer estanque à convenção, ${ }^{36}$ o presente artigo considera serem raras as hipóteses em que o vício não contamina a sentença. ${ }^{37}$ Por isso, a teoria das invalidades também deve se pautar com relação à contaminação. ${ }^{38}$ Isso porque, em decorrência do princípio da causalidade, ${ }^{39} \mathrm{e}$ do que Dinamarco denomina de "efeito expansivo" das nulidades (DINAMARCO, 2017, p. 708-709), ${ }^{40}$ qualquer acordo simulado que implique "contaminação judicial", também terá como consequência a nulidade de todos os atos processuais subsequentes ao negócio inválido, se houver relação de implicação com o ato anterior (NOGUEIRA, 2018, p. $195) .^{41}$

Nesse sentido, é possível visualizar dois principais panoramas quando há contaminação da sentença: a) o primeiro quando o vício é descoberto ou alegado enquanto houve a duração do processo; b) o segundo quando o vício só é alegado posteriormente ao trânsito em julgado da sentença da relação processual com o negócio jurídico viciado.

Nos dois casos caberia indagar se seria possível sanar o vício, seja a partir da conversão de um novo negócio jurídico, seja por meio da validade do ato dissimulado. Se considerasse apenas a via do direito civil, a resposta seria não.

a lei viola o direito de ação e o direito de defesa como direito à prestação da tutela jurisdicional. Em consonância com o direito aplicável, violaria direitos fundamentais constitucionais e processuais (art. $5^{\circ}$, XXXV, CF, e $8^{\circ}$ e 140 do CPC). Nesse sentido é que seria justificável a ação rescisória, a fim de preservar a tutela jurisdicional que garantisse a preservação dos direitos dos indivíduos. Além disso, mesmo que o negócio jurídico processual seja ato dispositivo, e não precise de homologação do juiz, ele ainda tem o papel de fiscalizar e controlar os atos processuais a impedir eventuais objetivos ilícitos das partes, como na simulação.

36 Nesse caso poderia se discutir o caso de ser cabível ação anulatória para se invalidar a convenção processual, já que voltada contra o ato processual das partes e não da sentença.

37 Pedro Henrique Nogueira (2018, p. 192) sobre o assunto afirma que os atos processuais do juiz a priori apenas estarão suscetíveis de invalidação, se o vício dos negócios jurídicos processuais contaminar o provimento judicial.

38 Liebman, sobre o assunto, afirma que o ato processual não pode ser visto de forma isolada, mas sim ligado a um procedimento conexo, cujos atos são ligados entre si por um vínculo de dependência. Por isso, a nulidade de um ato se comunica àqueles que o pressupõe. Por isso da nomenclatura "contaminação", e do mesmo jeito que se faz com os focos de uma epidemia, poderia se conter a expansão destes, através do "princípio da conservação dos atos processuais". Para completar, o autor ainda acrescenta que se a nulidade afetar o próprio procedimento, de modo a impedir o seu escopo, ficam inutilizados também os atos anteriores, que em si mesmo seriam válidos (LIEBMAN, 1984, p. 262).

39 Art. 248 CPC/1973 (repetido ipsis litteris em art. 281 CPC): “Anulado o ato, consideram-se de nenhum efeito todos os subsequentes que dele dependam, todavia, a nulidade de uma parte não prejudicará as outras que dela sejam independentes".

40 Isto decorre da própria noção de que o processo não deve ser analisado em compartimentos estanques, mas sim dentro dos feixes complexos de suas interações e das suas fases por qual passa.

41 No mesmo sentido, ao citar o princípio da causalidade dos atos processuais, Alexandre S. Marder (2010, p. 63): o autor menciona que os atos processuais guardam, muitas vezes, recíproca relação de interdependência, visto a indispensável organização interna dele. Por isso, sempre que constatada essa relação de dependência entre os atos processuais, o ato dependente daquele revestido pela invalidade, também deve ser considerado inválido. 
No direito processual, de forma contrária, a resposta seria predominantemente sim. ${ }^{42}$ Essa convalidação ocorre pela preclusão, quando dependentes da alegação das partes; e de regra, pela coisa julgada decorrente de trânsito em julgado da sentença proferida (MELLO, 2008, p. 235-237).

Além disso, a possibilidade decorre também dos princípios que orbitam a esfera da teoria das invalidades: da liberdade das formas, instrumentalidade, ${ }^{43}$ preclusão, interesse, causalidade, fungibilidade, primazia do julgamento de mérito (SICA, 2019, p. 292-293), e a máxime pas de nullité sans grief (não há invalidade sem prejuízo). ${ }^{44}$

Nesse sentido, antes de invalidar o ato, deve-se analisar tais peculiaridades do caso concreto. Por isso, não havendo prejuízo do escopo pretendido pelas partes na esfera macroscópica, aparentemente nada impediria a continuidade da demanda, ${ }^{45}$ havendo a preservação dos atos realizados até então. Mas isso só seria possível com a conversibilidade ou sanabilidade do vício, ou em caso da existência de ato dissimulado. ${ }^{46}$ Sem prejuízo, entretanto, da imposição de eventuais sanções aos responsáveis pelo ato simulado, como a responsabilidade processual pela litigância de má-fé (art. 77, I, CPC) e do abuso do direito, responsabilidade civil em eventuais danos a terceiros (art. 927 CC), e até mesmo há de se cogitar em responsabilidade penal das partes, pela configuração

42 A convalidação dos atos processuais se justifica pela própria função que um ato tem quando apreciado em concomitância com os objetivos dos demais atos, com os quais se ligam segundo uma ordem determinada e em virtude de buscarem o mesmo fim: possibilitar o correto exercício da função jurisdicional (GRINOVER; GOMES FILHO; FERNANDES, 2009, p. 22).

43 Muitos acreditam que a instrumentalidade do processo na seara das nulidades seria uma inovação processual recente, como José Roberto dos Santos Bedaque (2011, p. 1), o qual afirma em seu texto que a terceira fase processual é a que estamos adentrando, caracterizado pela consciência da instrumentalidade. No entanto, a ideia já era defendida pela doutrina italiana mais antiga e já vem sendo reafirmada há mais de um século no Brasil. Por isso, há os que destacam a pouca reforma que passou a presente teoria estudada, já que até o próprio princípio instrumentalidade foi apenas uma "renovação ilusória" (CABRAL 2010, p. 89).

${ }^{44} \mathrm{O}$ Enunciado n. 16 do FPPC traz a máxime de que não pode haver invalidade se não houver prejuízo efetivo: "O controle dos requisitos objetivos e subjetivos de validade da convenção de procedimento deve ser conjugado com a regra segundo a qual não há invalidade do ato sem prejuízo".

45 Para Calmon de Passos (2002, p. 146-147), sempre que se perde ou se diminui uma faculdade processual, há lesão ou prejuízo para a parte, ficando demonstrado que tal faculdade poderia gerar influência no resultado final do processo. Assim, se o juiz, ao reconhecer a nulidade poderia evitar o efeito do vício sobre todo o processo, ensejando oportunidade de renovar o ato, aperfeiçoá-lo ou realizá-lo, o caso seria de nulidade sanável. Porém, se a nulidade fosse daquelas que repercutem sobre a validade da relação processual, conduzindo à extinção do processo sem julgamento de mérito, então a hipótese seria de nulidade insanável. No entanto, cabe a crítica ao autor quando se percebe que Calmon de Passos se detém nas finalidades do ato, sem perceber que, muitas vezes, a finalidade do ato não se confunde com as finalidades do processo.

46 Na simulação ainda há uma peculiaridade que se refere a ela poder ser classificada como inocente ou nocente, ou ainda absoluta ou relativa. Nesse quesito, e trazendo para o plano processual, utilizando-se como exemplo uma colusão absoluta, em que as partes nada quiseram na convenção processual realizada, caberia indagar se não seria o caso de inexistência do ato jurídico. Cabendo apenas se cogitar quanto aos outros efeitos reflexos no processo, se também não foram queridos. No entanto, em caso de colusão relativa, caberia a discussão quanto a invalidade. 
do crime de estelionato, em que o judiciário é a vítima do meio fraudulento para a configuração do crime (COZER, 2014).

Em suma, apenas diante da impossibilidade de ultrapassar o vício é que se deve declarar a invalidade de um ato (MATOS, 2015, p. 76), já que afeta o processo como um todo. Daí a necessidade de se analisar o panorama e as peculiaridades do caso na aplicação da teoria das invalidades no processo, e não se fixar a critérios fixos e estanques.

Conclusão

O presente artigo teve como escopo trazer breves reflexões sobre uma possível aplicação da teoria das invalidades processuais conforme o caso concreto. $\mathrm{O}$ caso utilizado para eventual análise foi o da colusão nas convenções processuais, por se tratar de um assunto de pouco enfoque na doutrina, assim como os demais vícios deste negócio jurídico. $\mathrm{O}$ assunto carece de estudos em relação às suas possibilidades e aplicações práticas. Por isso, há uma grande necessidade de se trazer enfoque aos vícios que podem surgir com o ato jurídico, tanto para se analisar suas consequências, quanto para se preveni-lo.

Nesse sentido, a colusão processual nas convenções poderia ocorrer de duas formas: uma, sem influenciar a sentença que lhe foi consequente; outra contaminando a sentença como um todo. A última hipótese foi o objeto da reflexão do presente artigo por entender que sua ocorrência é muito maior.

As discussões trazidas, relativas à contaminação da sentença pelo ato jurídico viciado, decorreriam da possibilidade de se sanar o vício, conforme os princípios que orbitam as invalidades e também da preclusão ou coisa julgada, além do cabimento de extensão interpretativa do art. 966, III do CPC para se rescindir a sentença viciada, em caso de sentença já transitada em julgado. Em caso de sentença ainda não transitada, caberia ação anulatória.

Portanto, a sanabilidade dos outros atos processuais sucessivos do ato viciado deve ser possível, caso não haja prejuízo dos atos processuais consequentes como um todo. Isso decorre dos princípios da teoria das invalidades, como o que visa preservar ao máximo o ato se não houver prejuízo (pas de nullité sans grief). Para tanto, poderia se analisar as antigas classificações do CC/2016 que subdividiam as categorias dos atos simulados em nocentes ou inocentes, ou absoluto e relativo para que se decretasse o prejuízo em uma colusão nas convenções processuais e assim a sua invalidade. Nesse sentido, apenas se não fosse possível convalidar o ato é que se deveria decretar a invalidade. Daí se teria a mais concreta aplicação da teoria das invalidades processuais: em conformidade às 
peculiaridades do caso concreto e não com critérios estanques e fixos, que, muitas vezes, não condizem com a realidade.

São Paulo, 28 de fevereiro de 2020.

\section{Referências}

ABDO, Helena Najjar. O abuso do processo. São Paulo: Revista dos Tribunais, 2007.

ARAGÃO, Leandro Santos; DIDIER JUNIOR, Fredie; LIPIANI, Júlia. Negócios jurídicos processuais em contratos empresariais. In: DIDIER JUNIOR, Fredie (coord.). Ensaios sobre os negócios jurídicos processuais. Salvador: JusPODIVM, 2018.

BEDAQUE, José Roberto dos Santos. Efetividade do processo e técnica processual. 3. ed. São Paulo: Malheiros, 2010.

BEDAQUE, José Roberto dos Santos. Nulidade processual e instrumentalidade do processo. In: WAMBIER, Luiz Rodrigues; WAMBIER, Teresa Arruda Alvim (org.). Doutrinas essenciais: processo civil. São Paulo: Revista dos Tribunais, out. 2011. v. 3, p. 985-1.003.

BEVILAQUA, Clóvis. Código civil dos Estados Unidos do Brasil: comentado. 3. ed. São Paulo: Livraria Francisco Alves, 1927. v. 1.

CABRAL, Antonio do Passo. Convenções processuais. Salvador: JusPODIVM, 2016.

CABRAL, Antonio do Passo. Nulidades no processo moderno: contraditório, proteção da confiança e validade prima facie dos atos processuais. 2. ed. Rio de Janeiro: Gen: Forense, 2010.

CÁMARA, Héctor. Simulación en los actos jurídicos. Buenos Aires: Depalma, 1944.

CARNELUTTI, Francesco. Sistema di diritto processuale civile. Padova: CEDAM, 1936. Tomo II: Atti del processo.

COLUSÃO. In: FRANÇA, Rubens Limongi. Enciclopédia Saraiva do direito. São Paulo: Saraiva, 1977. v. 16, p. 150-151.

COZER, Ricardo Araújo. Ação rescisória de decisão ou acordo judicial viciado em decorrência de colusão entre as partes: responsabilização civil e criminal dos conluiados e suspensão do efeito de extinção do processo sem resolução do mérito. LTr Suplemento Trabalhista, São Paulo, v. 50, n. 99, p. 455-460, jan./dez. 2014.

DAVIS, Kevin E.; HERSHKOFF, Helen. Contracting for procedure. In: CABRAL, Antonio do Passo; NOGUEIRA, Pedro Henrique Pedrosa (coord.). Negócios processuais. Salvador: JusPODIVM, 2015. (Coleção grandes temas do novo CPC; 1).

DIDIER JÚNIOR, Fredie. Negócios jurídicos processuais atípicos e execução. In: DIDIER JÚNIOR, Fredie (coord.). Ensaios sobre os negócios jurídicos processuais. Salvador: JusPODIVM, $2018 \mathrm{a}$. 
DIDIER JÚNIOR, Fredie. Negócios jurídicos processuais atípicos no CPC-2015. In: DIDIER JÚNIOR, Fredie (coord.). Ensaios sobre os negócios jurídicos processuais. Salvador: JusPODIVM, 2018 b.

DINAMARCO, Cândido Rangel. Instituições de direito processual civil. 7. ed. São Paulo: Malheiros, 2017. v. 2.

FERRARA, Francesco. A simulação dos negócios jurídicos. Tradução de A. Bossa. São Paulo: Saraiva, 1939.

GAINO, Itamar. A simulação dos negócios jurídicos. São Paulo: Saraiva, 2007.

GRINOVER, Ada Pellegrini; GOMES FILHO, Antônio Magalhães. FERNANDES, Antonio Scarance. As nulidades no processo penal. 11. ed., rev. atual. e ampl. São Paulo: Revista dos Tribunais, 2009.

JUNQUEIRA DE AZEVEDO, Antonio. Negócio jurídico e declaração negocial: noções gerais e formação da declaração negocial. São Paulo: Saraiva, 1986.

KELSEN, Hans. Teoria pura do direito. Tradução de João Baptista Machado. São Paulo: Martins Fontes, 1999.

KERN, Christoph A. Procedural contracts in Germany. In: CABRAL, Antonio do Passo; NOGUEIRA, Pedro Henrique Pedrosa (coord.). Negócios processuais. Salvador: JusPODIVM, 2015. (Coleção grandes temas do novo CPC; 1).

LACERDA, Galeno. Despacho saneador. Porto Alegre: Livraria Sulina, 1953.

LIEBMAN, Enrico Tullio. Manual de direito processual civil. Tradução e notas de Cândido R. Dinamarco. Rio de Janeiro: Forense, 1984. v. 1.

MARDER, Alexandre Salgado. Das invalidades no direito processual civil. São Paulo: Malheiros, 2010 .

MATOS, Rafael Alfredi de. A invalidade dos atos processuais no processo civil. 2015. $150 \mathrm{f}$. Dissertação (Mestrado em Direito) - Faculdade de Direito, Universidade de São Paulo, São Paulo, 2015.

MELLO, Marcos Bernardes de. Teoria do fato jurídico: plano de validade. 8. ed. rev. e atual. São Paulo: Saraiva, 2008.

MIRANDA, Francisco Cavalcanti Pontes de. Tratado de direito privado. São Paulo: Revista dos Tribunais, 2012. v. 2: fatos jurídicos.

MIRANDA, Francisco Cavalcanti Pontes de. Tratado de direito privado. São Paulo: Revista dos Tribunais, 2012. v. 3: negócios jurídicos.

MITIDIERO, Daniel Francisco. Colaboração no processo civil: pressupostos sociais, lógicos e éticos. 3. ed. rev., atual. e ampl. São Paulo: Revista dos Tribunais, 2015. 
MOREIRA, José Carlos Barbosa. Convenções das partes sobre matéria processual. Revista de Processo, São Paulo, v. 9, n. 33, p. 182-191, jan./mar. 1984.

MOREIRA, José Carlos Barbosa. O neoprivatismo no processo civil. In: MOREIRA, José Carlos Barbosa. Temas de direito processual: nona série. São Paulo: Saraiva, 2007.

NOGUEIRA, Pedro Henrique Pedrosa. Negócios jurídicos processuais. 3. ed. Salvador: JusPodium, 2018.

PASSOS, José Joaquim Calmon de. Esboço de uma teoria das nulidades aplicada às nulidades processuais. Rio de Janeiro: Forense, 2002.

SICA, Heitor Vitor Mendonça. Comentários ao código de processo civil: da comunicação dos atos processuais até do valor da causa. Coordenadores José Roberto F. Gouvêa, Luis Guilherme A. Bondioli e João Francisco N. da Fonseca. São Paulo: Saraiva, 2019. v. 5.

SILVEIRA, Marco Antonio Karam. Invalidade processual. Revista dos Tribunais, São Paulo, v. 94, n. 841, p. 709-729, nov. 2005.

THEODORO JÚNIOR, Humberto. Curso de direito processual civil. 57. ed. Rio de Janeiro: Forense, 2016. v. 1.

WAMBIER, Teresa Arruda Alvim. Nulidades do processo e da sentença. 5. ed. São Paulo: Revista dos Tribunais, 2004. 
